\title{
Construction of Education Mode of the Academy System Based on Outstanding Talents Cultivation
}

\author{
Jian-Bin ZHANG ${ }^{1, a,{ }^{*},}$, Ying-Jie ZHANG $^{2, b}$ \\ ${ }^{1}$ Jiangsu University of Technology, Changzhou 213001, China \\ ${ }^{2}$ Jiangsu University of Technology, Changzhou 213001, China \\ a zjb@jsut.edu.cn, b glzyj@jsut.edu.cn \\ ${ }^{*}$ Corresponding author
}

Keywords: Outstanding Talents, Academy System, General Education, Tutorial System.

\begin{abstract}
Based on the practical demand of developing outstanding talents, this article proposes a new mode of cultivating outstanding talents by using the modern university academy system as a platform, namely, the Outstanding Academy System. The implementation of this system will collect excellent students, integrate quality resources of the school, create a quality education environment, and innovate the model of educating students, thus offering an effective model for the innovation of the student education and management mode in cultivating outstanding talents.
\end{abstract}

\section{Introduction}

Since June 2010, the Ministry of Education has launched the training program for outstanding teachers, outstanding engineers, outstanding doctors and outstanding lawyers (" the Outstanding Program "). Launch of "Outstanding Program" is an important measure, signifying that China's higher education actively serves the national development strategy in the new era. The program builds solid human resource advantages for China, which helps establish an innovation-oriented country and realize the industrialization and modernization. It will enhance core competitiveness and overall national strength of our country and will have an extensive and profound influence on comprehensively promoting the quality of higher education talent training. To this end, colleges and universities across the country have actively responded and started to carry out the exploration and practice of the cultivation of outstanding talents.

Based on the practical needs of training outstanding talents, this article discusses the framework and implementation plan of this new management mechanism of education for outstanding talents based on the modern college system --- the Outstanding Academy System, providing reference for innovating the training mode of outstanding talents and improving the quality of training.

\section{Connotation of the Outstanding Academy System}

\section{Basic Quality and Ability of Outstanding Talents}

The concept of "outstanding talent training" comes from the "Education Training Program for Outstanding Engineers", or "Outstanding Program", launched by the Ministry of Education in 2010. According to the document released by the Ministry of Education on the training 
program for outstanding talents, the basic quality and ability of outstanding talents lie as follows: (1) a sense of responsibility: a kind of mental state that consciously and actively performs all the beneficial things, whatever the thing done is the person's duty or not; have positive life values and a strong sense of social responsibility; (2) innovation ability: be able to adapt to the highly competitive and constantly changing learning and working environment, and be able to constantly propose new ideas, new methods and new strategies for the problems, and put them into practice; (3) adaptability: be able to meet the demands of the job, and quickly adapt to the working environment, find problems and solve them; (4)internalized ability: basic ability to communicate, cooperate and compete in an international perspective and cross-cultural environment.

\section{Academy System}

In recent years, as a new management mode of student education, academy system has become a hot spot in China's higher education reform. According to incomplete statistics, more than 70 colleges and universities in mainland China have implemented the academy system reform. The study found that the academy system nowadays in China has the following common features: it learns from Chinese ancient academy's education essence of "people-oriented" spirit and the contemporary residential college system in foreign countries to establish a kind of student education and management system, which implements general education on students as well as the education of morality and behavior. Through general education and non-formal education, academy system also introduces the credit system, and promotes academic and cultural events. Besides, the arrangement of accommodation mixes these students at different grades and majors so as to encourage students from different backgrounds to communicate with and learn from each other. Like this, students of liberal arts and science become roommates. This will help achieve subject complementation, develop students' personality, improve the personality education, and improve students' comprehensive qualities and all-round development.

\section{Outstanding Academy System}

Based on the practical needs of colleges and universities of cultivating outstanding talents in the new era, this article proposes a new management mode of talent education based on the academy system, namely, Outstanding Academy System. Outstanding Academy System adheres to a "student-oriented" education idea, and inherits the spirit of "teaching is a kind of learning" and "let a hundred schools of thought contend", which is held by Chinese ancient academies. It also fuses "humanistic spirit" of Chinese traditional culture, learns from foreign residential colleges' "general education" concept, and pays high attention to students' growth and maturity of thoughts, behavior formation, personality shaping and quality promotion. Taking the student apartment community as the implementation platform, Outstanding Academy System gives full play to the educational function of the tutorial system. Coordinating with professional education, the system organically integrates general education and informal education, integrates students study, life management services, and personal development, integrates professional education, human education and social citizen education. In this way, the school running advantage can be transformed into the advantage of talent cultivation quality, and excellent talents with all-round development of morality, intelligence and physical ability and great development potential are trained. 


\section{Positioning of Education Function of the Outstanding Academy}

\section{Outstanding Academy is Aimed at General Education}

Outstanding program is an industry-oriented, world-oriented, and future-oriented program that trains students to be outstanding talents who are willing to work on the frontline of the industry. Obviously, the realization of the training goal of outstanding talents should be guaranteed by a sound cultivation system. In terms of education content, this system should include both professional education and general education. In terms of the education channel, this system should include both education in the first classroom and non-formal education in the second classroom. If professional schools are mainly responsible for students' professional education, then carrying out the general education is the main job of the outstanding academy. Professional education emphasizes the professional characteristics of people, with the main purpose of imparting professional knowledge and cultivating students' professional ability. Therefore, students can be fully developed in their professional fields, and the goal of cultivating high-level professional talents for the country can be achieved in this way[1]. General knowledge education emphasizes people-oriented concept, and it focuses on the release of human's free spirit and the awakening of human's subjective spirit. It believes that the essence of education is to cultivate free people, healthy people rather than instrumental people, and it is to cultivate people with their unique personalities rather than people with obedience[2]. Under the guidance of the "holistic education", the professional education in the professional school and education of the general knowledge in the outstanding academy together constitute the cultivation system of outstanding talents. It can be said that the cooperation and division of labor between professional schools and outstanding academies are the basic requirements for the cultivation of outstanding talents.

\section{The General Education System for Outstanding Academy}

General education in the outstanding academy includes formal education and non-formal education[3]. Formal education mainly focuses on in-class learning. According to the requirements of the outstanding program for the general ability of outstanding talents, the general courses in the outstanding academy can include courses like professional ethics and social participation, spirit of excellence and innovation ability, cultural inheritance and classics of literature and history, communication and team cooperation, ecological environment and caring for the life, international vision and multi-culture etc. The non-formal education in the outstanding academy is positioned as the second classroom education, which emphasizes the concept of "unity of knowledge and practice" and focuses on cultivating students' cultural taste, self-confidence, the sense of responsibility, organizational coordination and interpersonal skills. Non-formal education and formal education depend on each other, which is not only a supplement to education in the first classroom, but also a development to education in the first classroom. Through the flexible, diverse and distinctive college life in the second classroom, students can integrate theory with practice and shorten the distance between university and society (ideal and reality). At the same time, the college life integrated with interdisciplines is more conducive to students' active participation, broadening their horizons and improving their abilities[4]. 


\section{Construction Plan of Outstanding Academy}

\section{Construction Goal}

Outstanding academy is not only a place for students to live, but also the place for learning and communication. Therefore, outstanding academies should focus on the construction of infrastructure and supporting facilities, so that academies will become the home for students. The construction goal of outstanding academies is to gather brilliant students, integrate high quality resources, and innovate education mode to offer a good learning and living environment for students, and let different students intermingle. In this way, the outstanding academy can be built as a comprehensive community for students to study, live and grow themselves, can be built as a platform that allows students to develop their moral character and communicate their ideas, and can be built as an all-weather training base for outstanding talents.

\section{Construction Principles}

(1) Adhere to the student-oriented concept. "People-oriented" concept is the basic value of education. In the process of building the outstanding academy, students' comprehensive development and individual development are the primary goal. It inspires students' learning interest and learning potential, and motivates them to pursue excellence. We should adhere to the principal status of students, enlarge their rights of self-management and self-development, improve their degree of autonomy, and cultivate their sense of belongings through students' participation in the management of the academy. It is necessary to establish the working ethic of serving students to their growing into talents, respect students, get along with students, and treat them as equal. In this way, a harmonious relationship between teachers and students can be formed, and teachers can become students' confidant and play their leading role.

(2) Form synergy with professional colleges. The students who enter outstanding academies have a dual identity. They are affiliated to academies and also they are students of the professional colleges. Therefore, they are taught and managed by both outstanding academies and the professional colleges. The training objective of outstanding academies and professional colleges is aimed at cultivating outstanding talents and their outstanding talent cultivation programs should make clear their respective positioning of the cultivation, so that the general knowledge education and professional education can form a joint force in the process of cultivating outstanding talents.

(3) Enhance the vitality of the outstanding academy. The outstanding academy is a study, living and self-education system organized by all students living there according to certain rules[5]. Therefore, in the process of construction and operation, universities need to endow outstanding academies with a certain degree of autonomy and stimulate the vitality. we should actively develop the financing channels to provide financial guarantee for outstanding talent cultivation.

\section{The Main Content of Construction}

(1) Establish the high-quality education teaching resources that meet requirements of cultivating outstanding talents, including the relatively independent, high-end apartment community with the academy's characteristic, teacher offices, special classroom for general education, library, electronic reading-room, education platform for humanistic quality, platform for scientific research quality development and ability training, and all kinds of hardware 
resources, such as the student center and general education courses[6]. By planning the function layout of the academy community, students who enter the academy can fully contact and interact with teachers, which will effectively combine students' living space and learning space. Students can discuss with each other, learn from each other and improve together. At the same time, it also provides students with independent management space, allowing students who enter the academy to develop their personal strengths according to their own interests, and carry out community activities together with their tutors and peers[7].

(2) Tutor team building. The implementation of the tutorial system is the feature of the academy. Based on the social needs and individual differences, tutors put forward some suggestions on the cultural construction of the academy, student activity plan and activity content. Through the communication and interaction with students, tutors can master the ideological, psychological and learning status of students, and offer timely guidance and support, which will promote the healthy development of cooperation between tutors and students. This establishment of a close relationship between tutors and students helps tutors become spiritual, ideological and learning guides for students. In the academy's education activities, apart from the general education courses, tutors can guide students to actively participate in all kinds of innovative activities, and various subject competitions, etc. In addition, they can guide students' thesis writing, and guide students to carry out all kinds of special reading salons, quality development activities, personalized auxiliary activities, community activities, social public welfare activities and so on.

(3) Academy culture construction[8]. The essence of academy development lies in the construction of culture and the academy culture construction is an important standard for forming the academy. The academy culture permeates every part of the campus like air, which has an important influence on students' personality progress, inner self-cultivation and comprehensive quality improvement. The culture of outstanding academy needs to be formed in the communication between students and teachers, the communication between students and students, and the community activities of the academy. Tutors' personal charisma, wise thinking and moral quality will educate students, subtly influencing students, and students' concern, care and participation in the management of the community will all help form the academy culture. The academy can also form a unique concept of education by focusing on its own characteristics, and build a strong cultural atmosphere of the academy, including the academy banner, emblem, song, motto, journal, the academy festival, the official WeChat, the official microblog and the academy's cultural derivatives, which help build a strong cultural atmosphere.

(4) Student association construction. Based on personal interests and hobbies, student associations are mass organizations that voluntarily organized by students. Student associations' principles are self-education, self-management, self-discipline. These associations play to serve students, promote the individual qualities, and enrich campus life, which will realize the purpose of the mutual influence between the academy and students as well as common development. The academy should give students sufficient freedom, and attract students to actively participate, so that the cultivation of students' moral quality and the formal courses developed by the academy complement each other. Student associations also serve as a bridge of communication between administrators and students, facilitating the face-to-face communication between teachers, administrators and students, and thereby subtly influencing students' learning and moral development. 
(5) Organization and system construction. In terms of the external environment, the current "Double World-class" strategy and the comprehensive reform of higher education will provide more free space for the development of the outstanding academy. Within university, the organization, rules and regulations of the outstanding academy should been established, such as appraisal system, reward system, communication system, etc. These systems will clearly stipulate the work target and responsibility division, make scientific positioning for management personnel, enhance the professionalization of management, and build and perfect a multi-dimensional guarantee system for outstanding talent cultivation.

\section{Summary}

The cultivation of outstanding talents is not only the objective need of China's economic and social development, but also the realistic requirement of higher education's educational mission, as well as the internal requirement of students' all-round development, growth, and pursuit of excellence. By combining outstanding talents cultivation program with ancient Chinese academy system and foreign residential college model, a new education management model based on outstanding talent cultivation is formed, which will provide a new model and a reference for outstanding personnel education and training.

\section{Acknowledgement}

This research was financially supported by 2015 Jiangsu Higher Education Educational Reform Research Project "Innovation Research on Education Mode of the Academy System based on Outstanding Talents Cultivation” (No. 2015JSJG153).

\section{References}

[1] Xiao-Juan HU, Discussion on the Dialectical Relationship Between General Education and Professional Education, 10 (2014) 15-18.

[2] Chuan YUAN, On the Effective Combination of “General education" and "Professional Education”, 278 (2014) 3-3.

[3] $\mathrm{Yu}$ ZHUANG. General Education Curriculum System of Colleges of Modern Universities-Based on the Study of 15 Colleges in Greater China,Journal World Education,378 (2015), 66-71.

[4] Jian-Min WANG. Study on the General Education Model of "Curriculum-academy”, Education Review, 12 (2014), 35-37.

[5] Hai-Yan LIU. The Status, Problems and Strategy of Academy System Reform in Modern Universities,China Higher Education Research, 11 (2017), 43-48.

[6] Zheng GONG,Jian-Min WANG,Hui ZHONG, Xing-Hong Jiang, Dveloping Outstanding Doctors: Exploration of Reform Measures Based on Academic Learning System, China Higher Medical Education,8 (2013),40-43.

[7] Rong-Rong ZHONG, Cheng-Zhen LV, A Probe into the Management Mode of Academic Schooling System by Honors College, Meitan Higher Education,5(2014),81-85. 
[8] Zhuo-Ning DONG,Jian-Li QI, Research on Personalized Education of Modern Colleges under the Background of "Double World-class" Construction-A Case Study of Beihang University,6 (2016),95-98. 